\title{
Antibiotic Practicing Habits, Knowledge and Attitude toward Education about Antibiotics among Dentists in Jazan City
}

\author{
Nasser Ibrahim Zakri ${ }^{1}$, Nasser Mohammed Alshehri ${ }^{1}$, Abdulrahman Nasser Shebli ${ }^{1}$
}

${ }^{1}$ Dentist General Practitioner, Faculty of medicine, Jazan university, Jazan

\section{ABSTRACT}

Introduction: Inappropriate use of antibiotics not only drives antibiotic resistance and misuses resources but also increases the risk of potentially fatal reactions and exposes people to unnecessary side effects and unfavorable outcomes ranging from gastrointestinal disturbances to fatal anaphylactic shock. In developed countries, surveys about general dental practitioners' prescribing habits have raised awareness of the quality of prescriptions of antibiotics. Whilst some surveys have emphasized that dental prescriptions do not follow clinical guidelines, other authors have concluded that there is a lack of scientific information about appropriate and efficient prescription of proper antibiotic. Moreover, changes in the dental pharmacotherapeutic field have been so rapid in recent years that necessitate the constant updating of dental practitioners' knowledge about new drugs, drug interactions, and useful therapeutic trends is necessary.

Methods: We have conducted a descriptive cross-sectional study among dentists and dental trainee in Jazan city. The questionnaire required information about antibiotic prescription habits, knowledge about preventive majors of dental infection, and followed approaches in dental emergencies. Data collected through distribution of online filled questionnaire. The participants filled the questionnaire online then resent it again to the researcher. The distributed questionnaire was in Arabic language to overcome the language barrier. Collected data verified and coded before its entry to Statistical Package for the Social Science (SPSS).

Results: Participants were classified into four categories by age: from 20 to 24 years (30.9\%), from 25 to 30 years (53.9\%), from 31 to 35 years $(8.6 \%)$ and above 35 years $(6.6 \%)$. More than half of participants were Dental graduates $(56.4 \% \%),(37 \%)$ were students and Interns, $(6.2 \%)$ were with Master/ Diploma and only one of them with $\mathrm{PhD}(.4 \%)$. The majority of participants prescribed antibiotic for acute apical abscess (72.8\%), on the other hand, less than half of participants (45.7\%) prescribed antibiotics for acute apical abscess without systemic involvement, and nearly two thirds $(65.4 \%)$ of participants prescribed antibiotic for medically compromised patient after tooth extraction.

Conclusion: It is alarming that most dentists do not perform a proper microbial diagnosis before selecting an antibiotic as adjunct periodontal therapy. As a result, they tend to prescribe broad spectrum antibiotics depending on the probability and most likely diagnosis. Also, the misconception of indications for antibiotic prescription and low knowledge about antibiotics assist in the misuse and in proper use of antibiotics.Educational initiatives and continuous refreshment of knowledge may prevent unnecessary prescription in endodontic emergency treatments.

Keywords: Dental, Awareness, Antibiotic, Prescription, Abscess, Communication, Education

\section{INTRODUCTION}

Dentists commonly prescribe medications for common oral conditions, mainly infections ${ }^{(1)}$, they prescribe between $(7 \%)$ and $(11 \%)$ of all common antibiotics ${ }^{(2)}$, and their prescription for antibiotics has become an important aspect of dental practice. In dentistry, antibiotic prescription is empirical because the dentist does not know what microorganisms are responsible for the infection, as samples from the root canal or periapical region are not commonly taken and examined for culture and sensitivity. Thus, based on clinical and bacterial epidemiological data, the microorganisms responsible for the infections can only be suspected according to local facilities, and treatment is decided on a presumptive basis with broad spectrum antibiotics often being prescribed ${ }^{(3)}$. For this reason, antibiotics contribute to the vast majority of medications prescribed by dentists ${ }^{(4)}$. The use of

antibiotics as an adjunct in the management of orofacial infections is an important treatment option when

clinically indicated. However, systemic antibiotic prescription may be associated with unfavorable side effects ${ }^{(5)}$. Inappropriate use of antibiotics not only drives antibiotic resistance and misuses resources but also increases the risk of potentially fatal reactions and exposes people to unnecessary side effects and unfavorable outcomes ranging from gastrointestinal disturbances to fatal anaphylactic shock ${ }^{(6)}$. In addition, antibiotic prescription for common medical problems increases patient expectations for antibiotics, leading to a vicious cycle of increased prescribing in order to 
meet expectations of patients ${ }^{(6)}$. The increasing resistance problems of recent years are probably related to over- or misuse of broad spectrum antibiotics such as penicillin, cephalosporins and fluoroquinolones ${ }^{(7)}$. We have now entered an era where some bacterial species are resistant to the full range ofantibiotics presently available, such as but not limited to, the methicillin-resistant Staphylococcus aureus being the most widely known example of extensive resistance bacteria ${ }^{(4)}$. These serious complications associated with antibiotics use have encouraged studies investigating antibiotic prescribing practices of dentists ${ }^{(8-11,12-14)}$. In developed countries, surveys about general dental practitioners' prescribing habits have raised awareness of the quality of prescriptions of antibiotics ${ }^{(15)}$.

Whilst some surveys have emphasized that dental prescriptions do not follow clinical guidelines, ${ }^{(5)}$ other authors have concluded that there is a lack of scientific information about appropriate and efficient prescription of proper antibiotic (16). Moreover, changes in the dental pharmacotherapeutic field have been so rapid in recent years that necessitate the constant updating of dental practitioners' knowledge about new drugs, drug interactions, and useful therapeutic trends is necessary ${ }^{(17)}$. To achieve these needs, it is only possible with the help of continuing education programs, attending conferences, and reading various dental journals and dental magazines to gain appropriate knowledge on the use of drugs and their pharmacokinetics.Thus, lifelong learning in the subject following graduation is highly recommended. In Europe, several surveys have studied the pattern of antibiotic prescribing habits in the treatment of endodontic diseases and Amoxicillin was the firstchoice antibiotic prescribed in endodontic infection in most of the surveys ${ }^{(18,19)}$. Only in Turkey, it is reported that ampicillin was the first-choice antibiotic for endodontic infections ${ }^{(20)}$. In irreversible pulpitis, necrotic pulps and localized acute apical abscesses, antibiotics are unnecessary ${ }^{(21)}$.

A recent study evaluated the effects of systemic antibiotics provided with or without surgical intervention, with or without analgesics, for symptomatic apical periodontitis or acute apical abscess in adults in a recent Cochrane review and they concluded that there was very low-quality evidence, which was insufficient to determine the effects of systemic antibiotics in adults with symptomatic apical periodontitis or acute apical abscess ${ }^{(6)}$. The risk of adverse effects following systemic application and the ineffectiveness of systemic antibiotics in some pulpal and periapical conditions has led to the use of locally applied antibiotics in root canal treatment, that is within the canal system ${ }^{(22)}$. However, antibiotics do not reduce the pain or swelling arising from teeth with symptomatic apical pathosis $(6,16)$. beside routine endodontic therapeutic procedures, there are other strategies may be needed in patients presented with abscess formation. In these patients, the primary aim should be toward drainage of the abscess ${ }^{(22)}$. If the abscess was recognized to be discrete and localized swelling, drainage only is considered sufficient without introducing additional medication ${ }^{(23)}$. Topical antibiotic application for replantation of avulsed tooth is also advocated to enhance healing. Moreover, the use of topical antibiotics has been reported to be more beneficial compared with systemic antibiotics in cases presented with avulsed tooth ${ }^{(24)}$. Current Guidelines recommend systemic antibiotic therapy for patients going replantation of avulsed permanent tooth ${ }^{(24)}$.

\section{METHODS}

We have conducted a descriptive cross-sectional study among dentistry trainee and dentists of all degrees in Jazan city, Saudi Arabia. The study conducted through nine months duration (2018). We conducted the study among dentistry trainee including dentistry students and interns, dentist graduates, dentists with master or diploma, and dentists with $\mathrm{PhD}$ degree. The total sample obtained was 243.The data collection tool was a questionnaire prepared by the researcher and revised and approved by the local committee in Jazan University.

The questionnaire required information about antibiotic prescription habits, knowledge of preventive majors for dental infection, and followed approaches in dental emergencies.Data collected through distribution of questionnaire online by Arabic language to overcome the language barrier. The questionnaire consisted of four parts: first part included demographic information, and there was no personal information required to insure confidentiality of participants, second part included different scenarios about dental cases and asked participants whether if they prescribed antibiotics for them or not, second part included scenarios about dental emergencies and asked participants which treatment approach they will follow, third part included the mostly preferred antibiotic they prescribe to patients and perceived factors that affect the course (duration) of antibiotic, fourth part included questions about participant's communication and education among and their knowledge about preventive majors of dental infection. The page top contains a clarification to participants of the study and asking their consent to complete the questionnaire. 
The participants filled the questionnaire online and resent it again to the researcher. Collected data verified and coded before its entry to Statistical Package for the Social Science (SPSS). The questionnaire responses were analyzed using the Statistical Package for the Social Science (SPSS Inc. Chicago, IL, USA) version 23. Categorical variables were described by frequencies and percentagesand Chi-Square tests used to test the significance of association between categorical variables. The level of significance was set at $\mathrm{P}<0.05$.

\section{RESULTS}

Table 1 shows general characteristics of the participants. Participants were classified into four categories by age: from 20 to 24 years $(30.9 \%)$, from 25 to 30 years $(53.9 \%)$, from 31 to 35 years $(8.6 \%)$ and above 35 years $(6.6 \%)$. More than half of participants were Dental graduates $(56.4 \% \%)$, (37\%) were students and Interns, (6.2\%) were with Master/ Diploma and only one of them with $\mathrm{PhD}(.4 \%)$. For the duration in clinical practice in dentistry, nearly $(40 \%)$ of participants were in the clinical practice for less than three years, $(23.1 \%)$ of them for more than three years, and the remaining were either Student or Intern, $(21 \%)$ and $(16 \%)$ respectively.

Table 2 shows frequency of practicing antibiotic habits and scenarios participants would prescribe antibiotic for it and recognized indications for antibiotic prescription from participants preview. The majority of participants prescribed antibiotic for acute apical abscess $(72.8 \%)$ and it is the mostly agreed case as to prescribe antibiotic to treat it, on the other hand, on the other hand, less than half of participants $(45.7 \%)$ prescribed antibiotics for acute apical abscess without systemic involvement, nearly two thirds (65.4\%) of participants prescribed antibiotic for medically compromised patient after tooth extraction, $(60.2 \%)$ of them prescribed antibiotic for acute necrotizing ulcerative gingivitis (ANUG), (57.6\%) of them agreed prescribing antibiotic is the first choice for a patient came with (pericoronitis) with systemic involvement (trismus), less than half of participants (45.7) prescribed antibiotic for symptomatic apical periodontitis, also less than half of them (45.7) prescribed antibiotic for patient after replantation of avulsed tooth, nearly (40\%) of them agreed to that antibiotics is required and is the best choice for treatment and improvement for a patient with chronic apical abscess, and nearly a third of them (34.2\%) prescribed antibiotics for dry socket. The least cases participants prescribed antibiotics as follow: symptomatic irreversible pulpitis $(27.2 \%)$, oral cavity infection by herpes simplex virus (19.8\%), and the least case they prescribe antibiotic for it was a patient planned for multiple visits for root canal treatment $(11.5 \%)$.

Table 3 shows the emergency treatment approaches participants will follow in different dental emergency scenarios. For a patient presented with acute apical abscess, the majority of participants (64.3\%) prescribed antibiotics with drainage, few of them either will give antibiotics only if no drainage needed (18.9) or give antibiotics only (11.9), very few of participants did not know what to do $(4.9 \%)$. For a patient presented with oral infection with diffuse facial swelling, nearly half of participants $(51 \%)$ prescribed antibiotics with drainage, $(27.6 \%)$ of them were given antibiotics only, (15.6\%) of them were given antibiotics only if drainage needed, and few of them $(6.2 \%)$ did not know what to do. The emergency treatment approach participants will follow in case of a patient presented with necrotic pulp with symptomatic apical periodontitis were as follow: more than half of them $(53.1 \%)$ of them were given analgesia with operative intervention, nearly a third of them (34.2\%) were given antibiotics and analgesia with operative intervention, and few of them were either given antibiotics and analgesia together (7.4\%) or did not know what to do $(5.3 \%)$.

Figure 1 shows the commonly preferred antibiotics participants prescribed to patients for therapeutic reasons. The most commonly preferred antibiotic was amoxicillin (54.3\%), followed by Augmentin (amoxicillin and clavulanic acid) (30.5\%), and few of them chosed other types of antibiotics and they were as follow: penicillin (5.3\%), metronidazole $(2.5 \%)$, clindamycin $(1.8 \%)$, ampicillin $(.8 \%)$, erythromycin $(.8 \%)$, and $(4.5 \%)$ did not know what they prefer.

Figure 2 shows perceived factors that participants think it affects the course of antibiotic prescribed for a patient. The majority of participants said that the type of antibiotic, the type of infection (localized/ spreading), and clinical improvement of patient together are factors affect and determine the course of antibiotic prescribed for patient, $(11.1 \%)$ of them said it is the type of infection (localized/ spreading) that affects the course of antibiotic, (10.3\%) of them said it is the type of antibiotic that affects the course of antibiotic, and only (7\%) of them did not know what affects the course of antibiotic that will be prescribed for patient.

Table 4 shows participants knowledge about preventive measure against oral infection. The majority of participants (86\%) knew that oral hygiene measures play a major role against oral microbial infection and it is functioning asantimicrobial. In the 
same context, regarding orofacial infection, (72\%) them agreed to that elimination of the source of infection with using the proper type of antibiotic and oral hygiene measures will prevent recurrence of orofacial infection. Nearly a fifth of participants $(21 \%)$ agreed only elimination of the source of infection will prevent recurrence of orofacial infection, $(4.6 \%)$ of them agreed onlyusing the proper type of antibioticwill prevent recurrence of orofacial infection, and (1.6\%) of them agreed to that only oral hygiene will prevent recurrence of orofacial infection. Table 5 shows participants education about antibiotics and their knowledge for antibiotic resistance, and their communication with pharmacy and their patients regarding antibiotics. Attitude toward attending educational hours about antibiotics was low. More than two thirds of participants $(68.3 \%)$ did not participate in educational hours about antibiotics while nearly $(71 \%)$ of them read about antibiotic resistance. (78.2\%) of participants have a clinic and prescribe antibiotics, (46.3\%) of those who have a clinic have direct contact with pharmacy and they contact them, while $(56.7 \%)$ did not. Almost all of participants (97.1\%) communicated with their patients and told them to complete their antibiotic course (duration and dose) when they prescribe antibiotics to them.

Table 6 shows significant relations of antibiotics prescription habits and communication with pharmacy among age groups. There was a significant reversal relation between age and prescription of antibiotic for acute necrotizing ulcerative gingivitis (ANUG). The younger the age, the higher prescription of antibiotic for acute necrotizing ulcerative gingivitis (ANUG). More than two thirds from those who aged from $20-$ 24 years $(78.7 \%)$ prescribed antibiotics for acute necrotizing ulcerative gingivitis (ANUG) and they were significantly more than other age groups $(\mathrm{p}<0.001)$. More than half those who aged from $31-$ 35 years $(57.1 \%)$ prescribed antibiotics for acute necrotizing ulcerative gingivitis (ANUG) and they were significantly more than other older groups older $(\mathrm{p}<0.001)$. There was also a significant proportional relation between age and prescription of antibiotic for symptomatic apical periodontitis. The younger the age, the lower prescription of antibiotic for symptomatic apical periodontitis. More than half those who aged above 35 years $(56.2 \%)$ and those aged $31-35$ years (57.1\%) prescribed antibiotics for symptomatic apical periodontitis and they were significantly higher than the youngest age groups who aged from $20-24$ years $(29.3 \%)$ and those who aged from 25 - 30 years $(51.9 \%)(p=0.008)$. Among those who have a clinic and taking a part of their work on a clinic, there was a significant relation between their ages and their contact to pharmacy. There was proportional relation as the older of them, the higher contact with pharmacy $(p<0.001)$. The groups that contact with pharmacy were as follow: from older to younger ages: those whom aged above 35 years $(76.9 \%)$, those whom aged from 31 - 35 years $(60 \%)$, those whom aged from $25-$ 30 years $(53.7 \%)$, those whom aged from $20-24$ years $(16.3 \%),(\mathrm{p}<0.001)$.

Table 7 shows Significant relations of commonly preferred antibiotics to prescribe among Education. There is one participant with $\mathrm{PhD}$ and he did not what antibiotic he prefer to prescribe. The commonly preferred antibiotics were amoxicillin and Augmentin (amoxicillin + clavulanic acid). The most common antibiotic participants preferred to prescribe was amoxicillin. (55.6\%) of students and interns preferred to prescribe amoxicillin and (55.6\%) of dental graduates preferred to prescribe amoxicillin, and they were significantly higher than dentists with master/ diploma who preferred to prescribe amoxicillin (40\%), $(\mathrm{p}<0.001)$. The second most common preferred antibiotic to prescribe was Augmentin (amoxicillin + clavulanic acid). (35\%) of dental graduates preferred to prescribe Augmentin and (33.3\%) of dentists with master/ diploma preferred to prescribe Augmentin, and they were significantly higher than students and interns who preferred to prescribe Augmentin (23.4\%), $(\mathrm{p}<0.001)$.

Table 1: General characteristics $(n=243)$

\begin{tabular}{llc}
\hline \multicolumn{1}{c}{ Character } & & \\
\hline \multirow{4}{*}{ Age } & From 20 to 24 $(\mathrm{y})(\mathrm{n}(\%))$ & $75(30.9 \%)$ \\
& From 25 to 30 (y) $(\mathrm{n}(\%))$ & $131(53.9 \%)$ \\
& From 31 to 35 (y) (n(\%)) & $21(8.6 \%)$ \\
& Above 35 $(\mathrm{y})(\mathrm{n}(\%))$ & $16(6.6 \%)$ \\
\hline \multirow{3}{*}{ Education } & Student $(\mathrm{n}(\%))$ & $51(21 \%)$ \\
& Intern (n (\%)) & $39(16 \%)$ \\
& Dental graduate (n (\%)) & $137(56.4 \%)$ \\
& Master/ Diploma & $15(6.2 \%)$ \\
\hline
\end{tabular}




\begin{tabular}{llc} 
& & $1(.4 \%)$ \\
\hline Clinical & Student $(\mathrm{n}(\%))$ & $51(21 \%)$ \\
experience & Intern $(\mathrm{n}(\%))$ & $39(16 \%)$ \\
& Dentist $<3$ years $(\mathrm{n}(\%))$ & $97(39.9 \%)$ \\
& Dentist $>3$ years (n (\%)) & $56(23.1 \%)$ \\
\hline
\end{tabular}

Table-2: Antibiotic prescription habits and perceived indications for it

Question

Do you prescribe Antibiotics for Dry Socket

\section{Frequency Percent}

Yes $\quad 83$

160

$34.2 \%$

$65.8 \%$

Do you prescribe Antibiotics for Acute Necrotizing Ulcerative Gingivitis (ANUG)

Yes 146

No 97

$60.1 \%$

$39.9 \%$

Do you prescribe Antibiotics for Medically compromised patient after tooth Extraction

$\begin{array}{lcc}\text { Yes } & 159 & 65.4 \% \\ \text { No } & 84 & 34.6 \%\end{array}$

Do you prescribe Antibiotics after Replantation of Avulsed tooth

Yes

111

$45.7 \%$

No

132

$54.3 \%$

Do you prescribe Antibiotics for Symptomatic Irreversible pulpitis

$\begin{array}{lr}\text { Yes } & 66 \\ \text { No } & 177\end{array}$

$27.2 \%$

177

$72.8 \%$

Do you prescribe Antibiotics for Symptomatic apical periodontitis

Yes $\quad 111$

No 132

$45.7 \%$

$54.3 \%$

Do you prescribe Antibiotics for Acute Apical Abscess

Yes $\quad 177$

No 66

$72.8 \%$

$27.2 \%$

Do you prescribe Antibiotics for Acute Apical Abscess with no systemic involvement

Yes $\quad 111$

No 132

$45.7 \%$

$54.3 \%$

$132 \quad 54.3 \%$

Do you prescribe Antibiotics for a patient with oral infection by Herpes Simplex Virus (HSV)

$\begin{array}{lcc}\text { Yes } & 48 & 19.8 \% \\ \text { No } & 195 & 80.2 \%\end{array}$

Chronic apical abscess requires Antibiotics for improvement and is the choice of treatment Healing?

$\begin{array}{lll}\text { True } & 98 & 40.3 \%\end{array}$

False $\quad 145$

$59.7 \%$

Normally multiple visits are required for root canal treatment (RCT), would you prescribe Antibiotics between appointments

$\begin{array}{lcc}\text { Yes } & 28 & 11.5 \% \\ \text { No } & 215 & 88.5 \%\end{array}$

If a patient came with (pericoronitis) with systemic involvement (trismus), will you use Antibiotics as first choice

$\begin{array}{lll}\text { Yes } & 140 & 57.6 \% \\ \text { No } & 103 & 42.4 \%\end{array}$


Table-3: Treatment approaches for deffirintemergency dental problems

\begin{tabular}{lcc}
\hline Character & Frequency & \% \\
\hline Which of the following is your emergency treatment approach for & Acute apical abscess case? \\
Antibiotics only & 29 & $(11.9 \%)$ \\
Antibiotics only if no drainage needed & 46 & $(18.9 \%)$ \\
Drainage + antibiotics & 156 & $(64.3 \%)$ \\
I do not know & 12 & $(4.9 \%)$ \\
\hline Which of following is your emergency treatment approach for oral infection with diffuse facial \\
swelling? & 66 & $(27.2 \%)$ \\
Antibiotics only & 38 & $(15.6 \%)$ \\
Antibiotics only if no drainage needed & 124 & $(51 \%)$ \\
Drainage + antibiotics & 15 & $(6.2 \%)$ \\
I do not know & & \\
\hline Which of following is your emergency treatment approach for necrotic pulp with symptomatic \\
apical periodontitis? & 18 & $(7.4 \%)$ \\
Antibiotics + Analgesics & 129 & $(53.1 \%)$ \\
Operative intervention + Analgesics & 83 & $(34.2 \%)$ \\
Antibiotics + Analgesics + operative intervention & 13 & $(5.3 \%)$ \\
I do not know & & \\
\hline
\end{tabular}




\section{Commonly prescribed Antibiotic for therapeutic reasons (not prophylaxis)}

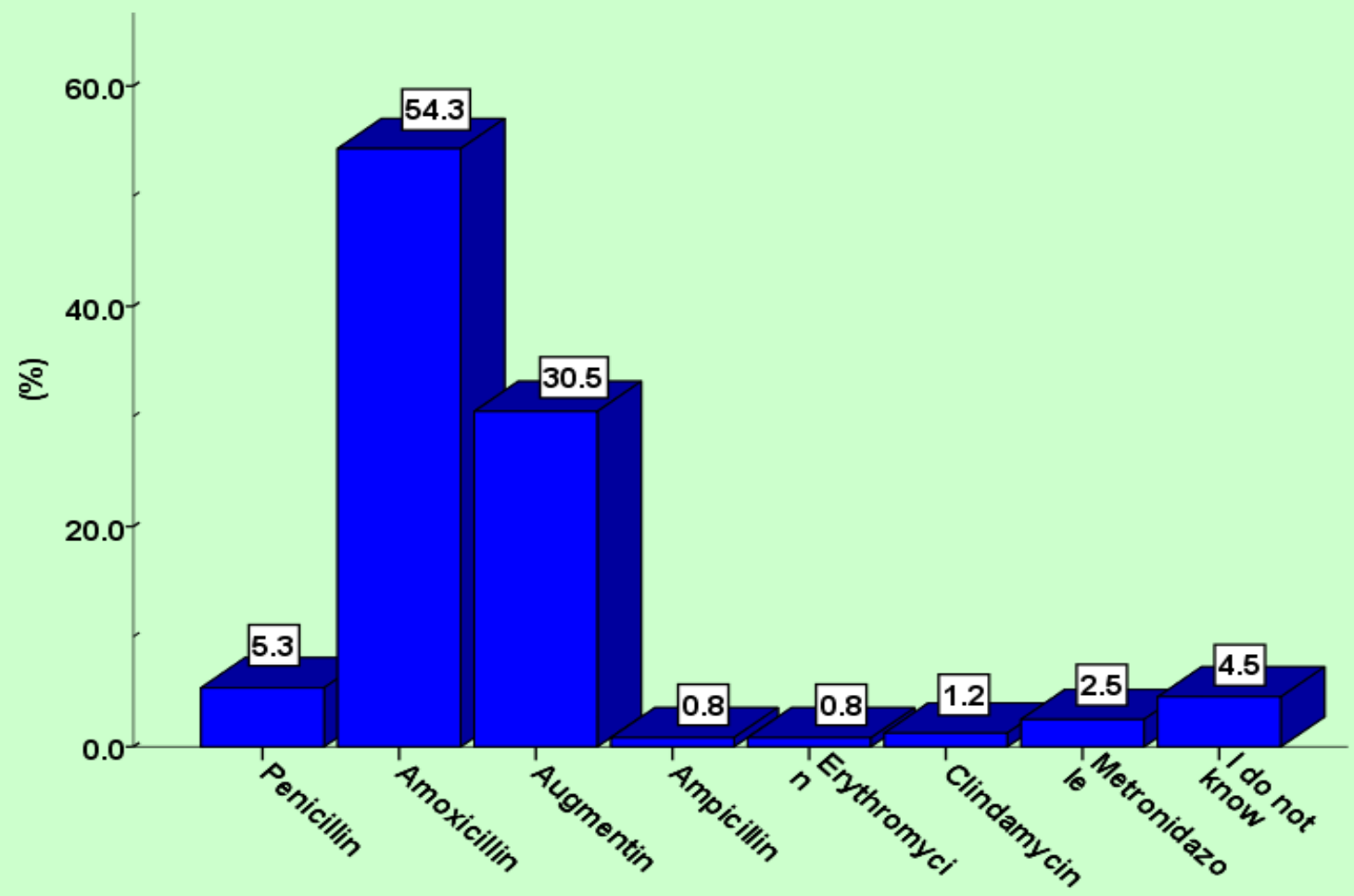

Figure-1: Commonly preferred antibiotics to prescribe 
The course of systemic Antibiotics treatment (duration) for Oral Infection depends on:



Figure-2: Perceived determinantsand effecting factors for the course of antibiotics

Table-4: Knowledge preventive measures of dental infection

\begin{tabular}{lcc}
\hline Character & Frequency & $\%$ \\
\hline $\begin{array}{l}\text { Oral Hygiene measures play major role against oral microbial infectionsas it isfunctioning as an } \\
\text { antimicrobial? }\end{array}$ & 209 & $(86 \%)$ \\
True & 34 & $(14 \%)$ \\
False & & \\
\hline To prevent recurrence of Orofacial Infection? & 53 & $(21.8 \%)$ \\
Eliminate the source of infection only & 11 & $(4.6 \%)$ \\
Use correct type of Antibiotics only & 4 & $(1.6 \%)$ \\
Oral hygiene measures only & 175 & $(72 \%)$ \\
All of the above & & \\
\hline
\end{tabular}

Table-5: Education about antibiotics and its resistant and participants Communication with pharmacy and patient about it 
Antibiotic Practicing Habits, Knowledge and Attitude...

\begin{tabular}{lcc}
\hline Have you ever been participated in any educational hours about & Antibiotics? & \\
Yes & 77 & $(31.7 \%)$ \\
No & 166 & $(68.3 \%)$ \\
\hline $\begin{array}{l}\text { Do you read about Antibiotics resistance? } \\
\text { Yes }\end{array}$ & 172 & $(70.8 \%)$ \\
No & 71 & $(29.2 \%)$ \\
\hline $\begin{array}{l}\text { Do you Have direct contact with Pharmacy in your clinic regarding antibiotics? And do you contact } \\
\text { them? }\end{array}$ & $\mathbf{5 3}$ & $\mathbf{( 2 1 . 8 \% )}$ \\
Have no clinic/prescription & $\mathbf{1 9 0}$ & $\mathbf{( 7 8 . 2 \% )}$ \\
Have a clinic & 88 & $(46.3 \%)$ \\
$\quad$ Have clinic (n=190) & 102 & $(56.7 \%)$ \\
\hline Do you tell your patient to complete his/her Antibiotics course (duration and Dose)? & \\
Yes & 236 & $(97.1 \%)$ \\
No & 7 & $(2.9 \%)$ \\
\hline
\end{tabular}

Table-6: Significant relations of antibiotics prescription habits and communication with pharmacy among age groups

Age groups

\begin{tabular}{|c|c|c|c|c|}
\hline Character & $\begin{array}{c}20-24 \text { years } \\
n=75\end{array}$ & $\begin{array}{c}25-30 \text { years } \\
n=131\end{array}$ & $\begin{array}{c}\text { 31-35 years } \\
\mathrm{n}=21\end{array}$ & $\begin{array}{c}\text { Above } 35 \\
\text { years } \\
n=16\end{array}$ \\
\hline
\end{tabular}

Do you prescribe Antibiotics for Acute Necrotizing Ulcerative Gingivitis (ANUG)?

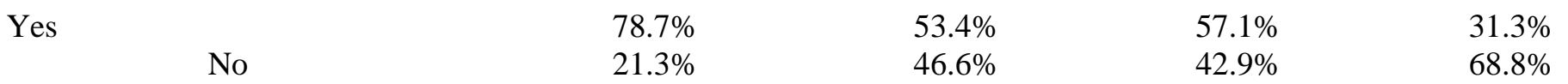

$(\mathrm{P}<0.001)$

Do you prescribe Antibiotics for Symptomatic apical periodontitis?

$\begin{array}{lcccc}\text { Yes } & 29.3 \% & 51.9 \% & 57.1 \% & 56.2 \% \\ \text { No } & 70.7 & 48.1 \% & 42.9 \% & 43.8 \%\end{array}$

$(\mathbf{P}=\mathbf{0 . 0 0 8})$

Do you Have direct contact with Pharmacy in your clinic?

No clinic/ prescription

Have a clinic

Have a clinic(n=190)

$\begin{array}{lr}\text { Yes } & (16.3 \%) \\ \text { No } & (83.7 \%\end{array}$

$34.7 \%$

$65.3 \%$

$\underline{n=49}$

$(83.7 \%$

$(\mathrm{P}<0.001)$

Table-7: Significant relations of commonly preferred antibiotics to prescribe among Education

$\begin{array}{lll}17.6 \% & 4.8 \% & 18.8 \%\end{array}$

$\mathbf{8 2 . 4 \%} \quad \mathbf{9 5 . 2 \%} \quad \mathbf{8 1 . 2 \%}$

$\underline{\mathrm{n}=108} \quad \underline{\mathrm{n}=20} \quad \underline{\mathrm{n}=13}$

$(53.7 \%) \quad(60 \%)$

$(40 \%)$

$(76.9 \%)$

$(23.1 \%)$

\begin{tabular}{|c|c|c|c|c|}
\hline & \multicolumn{4}{|c|}{ Age groups } \\
\hline Character & $\begin{array}{c}\text { Student/ Intern } \\
\mathbf{n}=90\end{array}$ & $\begin{array}{c}\text { Dental graduate } \\
n=137\end{array}$ & $\begin{array}{l}\text { Master/ Diploma } \\
n=15\end{array}$ & $\begin{array}{l}\text { PhD } \\
n=1\end{array}$ \\
\hline
\end{tabular}

Which antibiotic do you prescribe most often for therapeutic reasons (not prophylaxis)? 
Nasser Ibrahim Zakri et al.

$\begin{array}{lcccc}\text { Penicillin } & 7.8 \% & 4.4 \% & 0 \% & 0 \% \\ \text { Amoxicillin } & 55.6 \% & 55.5 \% & 40 \% & 0 \% \\ \text { Amoxicillin + clavulanic } & 23.4 \% & 35 \% & 33.3 \% & 0 \% \\ \text { acid (Augmentin) } & & & & \\ \text { Ampicillin } & 1.1 \% & .7 \% & 0 \% & 0 \% \\ \text { Erythromycin } & 1.1 \% & 0 \% & 6.7 \% & 0 \% \\ \text { Clindamycin } & 1.1 \% & 0 \% & 13.3 \% & 0 \% \\ \text { Metronidazole } & 3.3 \% & 2.2 \% & 0 \% & 0 \% \\ \text { Do not know } & 6.6 \% & 2.2 \% & 6.7 \% & 100 \%\end{array}$

\section{DISCUSSION}

Non-indicated clinical cases for antibiotic use include acute periapical infection, dry socket, and pulpitis ${ }^{(12)}$. Chronic inflammatory periodontal conditions are also not indicated for antibiotics; systemic antimicrobials should only be used in acute periodontal conditions where drainage or debridement is impossible, where there is local spread of the infection or where systemic upset has occurred ${ }^{(10)}$. Data reported from different countries indicated differences in dentists' knowledge of clinical situations indicated for antibiotics. Almost half or more of the dentists investigated in England ${ }^{(8)}$, Kuwait ${ }^{(12)}$, and Turkey ${ }^{(19)}$ would prescribe antibiotic for dry socket. In the current study,nearly a fifth of participants prescribed antibiotic for symptomatic irreversible pulpitis (27.2\%). There are studies done among the world and showed quit lower results as few of dentists prescribed antibiotics for irreversible pulpitis. A study done in Turkey at 2013 reported a result of $(6.1 \%)^{(19)}$, another study in United States also reported lower results $(16.8 \%){ }^{(25)}$, and a study done in Belgium reported $(4.3 \%)^{(15)}$. Another study done in Spain reported relatively higher result (40\%) ${ }^{(18)}$. Generally, the most commonly prescribed antibiotic by dentists in dental practice was Penicillin ${ }^{(13,14)}$, and the most popular one being amoxicillin ${ }^{(8,9,13)}$. In this study, the mostly preferred antibiotic participants prescribe was amoxicillin $(54.3 \%)$, followed by Augmentin (amoxicillin + clavulanic acid) $(30.5 \%)$. In the Turkish study, it showed lower results of amoxicillin (46.5\%) and higher results for Augmentin $(61.8 \%)^{(19)}$. In another studies, the result for Augmentin differed from our findings, a study in United states reported lower results $(3.1 \%)$ of participants prescribe Augmentin ${ }^{(25)}$ and another study in Belgium reported $(22.1 \%){ }^{(15)}$. And for the study that done in Spain, it was $(44.3 \%)$ of participants prescribe Augmentin ${ }^{(18)}$. In the current study, (72.8\%) prescribe antibiotic for acute apical abscess and this result increased to (64\%) if associated with drainage. A study done in Norway reported $(62 \%)$ of their participants occasionally prescribe such antibiotics to patients suffering from abscesses without symptoms. The study that done in Turkey showed lower results, it was $(41 \%)$ of their participants prescribed antibiotics only for acute apical abscess, and if there was drainage, then this rate rose to $(44.6 \%){ }^{(19)}$. In the current study, $(7.4 \%)$ of participants chosed to treat necrotic pulp with symptomatic apical periodontitis by antibiotics and analgesics together. The study that done in Turkey reported higher results as $(21.7 \%)$ of their participants chosed to treat acute apical periodontitis by analgesics and antibiotics ${ }^{(19)}$. The study done in Norway reported that (48\%) of participants prescribed antibiotics when treating periodontitis without the use of surgery. (44\%) percent reported using antibiotics when surgery was part of the treatment ${ }^{(11)}$. We reported few participants prescribed antibiotic for Herpes Simplex Virus (HSV) and they contributed to (19.8\%) while nearly similar result reported in a study done in Norway $(20 \%)^{(11)}$.

In conclusion, dentists tend to prescribe broad spectrum antibiotics depending on the probability and most likely diagnosis. Also, the misconception of indications for antibiotic prescription and low knowledge about antibiotics contribute in the misuse and in improper use of antibiotics.Prescribing practices of dentists can be improved by increasing awareness among dental practitioners of the recommended guidelines. Educational initiatives and continuous refreshment of knowledge may prevent unnecessary prescription in endodontic emergency treatments. Furthermore, the importance of initiating awareness programs among the general public should not be overlooked.

\section{REFERENCES}

1- Dar-Odeh N, Ryalat S, Shayyab M, and AbuHammad O (2008): Analysis of clinical records of dental patients attending Jordan University Hospital: documentation of drug prescriptions and local anesthetic injections. Therapeutics and clinical risk management, 4(5): 1111 
2- Cleveland J, and Kohn W (1998): Antimicrobial resistance and dental care: a CDC perspective. In Dent Abstr., 43(3): 108-10

3- PovedaRoda R, Bagán J, SanchisBielsa J, and Carbonell P (2007): Antibiotic use in dental practice: A review. Medicina Oral, Patología Oral y CirugíaBucal., 12(3): 186-192

4- Lewis M (2008): Why we must reduce dental prescription of antibiotics: European Union Antibiotic Awareness Day. British dental journal, 205(10): 537

5- Llor C, Cots J, Gaspar M, Alay M, and Rams N (2009): Antibiotic prescribing over the last 16 years: fewer antibiotics but the spectrum is broadening. European journal of clinical microbiology \& infectious diseases, 28(8): 893-897

6- Cope A, Francis N, Wood F, Mann M, and Chestnutt I (2014): Systemic antibiotics for symptomatic apical periodontitis and acute apical abscess in adults. Cochrane library, 6: retrieved from: http://dx.doi.org/10.1002/14651858.CD010136.pub2

7- WISe R, Hart T, and Cars O (1998): Antimicrobial resistance is a major threat to public health (editorial). BMJ., 317: 609-610

8- Palmer $\mathbf{N}$, Martin $\mathbf{M}$, Pealing $\mathbf{R}$, and Ireland $\mathbf{R}$ (2000): An analysis of antibiotic prescriptions from general dental practitioners in England. Journal of antimicrobial chemotherapy, 46(6): 1033-1035

9- Palmer N, Martin M, Pealing $\mathbf{R}$, and Ireland $\mathbf{R}$ (2001): Paediatric antibiotic prescribing by general dental practitioners in England. International journal of paediatric dentistry, 11(4): 242-248

10- Addy M, and Martin M (2003): Systemic antimicrobials in the treatment of chronic periodontal diseases: a dilemma. Oral diseases, 9(1): 38-44

11- Demirbas F, Gjermo $P$, and Preus $H$ (2006): Antibiotic prescribing practices among Norwegian dentists. Acta OdontologicamScandinavica, 64(6): 355359

12- Salako N, Rotimi V, Adib S, and Al-Mutawa S (2004): Pattern of antibiotic prescription in the management of oral diseases among dentists in Kuwait. Journal of dentistry, 32(7): 503-509

13-Al-Mubarak S, Al-Nowaiser A, Rass M, Alsuwyed A, Alghofili A, Al-Mubarak E, and Ho A (2004): Antibiotic prescription and dental practice within Saudi Arabia; the need to reinforce guidelines and implement specialty needs. Journal of the International Academy of Periodontology, 6(2): 47-55
14-Al-Haroni M, and Skaug N (2006): Knowledge of prescribing antimicrobials among Yemeni general dentists. Acta OdontologicaScandinavica, 64(5): 274280

15-Mainjot A, D'hoore W, Vanheusden A, and Van Nieuwenhuysen $\mathbf{J}$ (2009): Antibiotic prescribing in dental practice in Belgium. International endodontic journal, 42(12): 1112-1117

16-Keenan J, Farman A, Fedorowicz Z, and Newton J (2006): A Cochrane systematic review finds no evidence to support the use of antibiotics for pain relief in irreversible pulpitis. Journal of endodontics, 32(2): 87-92

17-Öcek Z, Sahin H, Baksi G, and Apaydin S (2008): Development of a rational antibiotic usage course for dentists. European Journal of Dental Education, 12(1): 41-47

18-Rodriguez-Núñez A, Cisneros-Cabello R, VelascoOrtega E, Llamas-Carreras J, Tórres-Lagares D, and Segura-Egea J (2009): Antibiotic use by members of the Spanish Endodontic Society. Journal of endodontics, 35(9): 1198-1203

19-Kaptan R, Haznedaroglu F, Basturk F, and Kayahan M (2013): Treatment approaches and antibiotic use for emergency dental treatment in Turkey. Therapeutics and clinical risk management, 9: 443

20-Kandemir S, and Ergül N (2000): Grievances in cases using antibiotics due to orodental problems and assessment of the need for antibiotics. International dental journal, 50(2): 73-77

21-Fouad A, Rivera E, and Walton R (1996): Penicillin as a supplement in resolving the localized acute apical abscess. Oral Surgery, Oral Medicine, Oral Pathology, Oral Radiology and Endodontics, 81(5): 590-595

22-Mohammadi Z, and Abbott $P$ (2009): Antimicrobial substantivity of root canal irrigants and medicaments: a review. Australian Endodontic Journal, 35(3): 131-139

23-Matthews D, Sutherland S, and Basrani B (2003): Emergency management of acute apical abscesses in the permanent dentition: a systematic review of the literature. Journal-Canadian Dental Association, 69(10): 660-661

24-Hinckfuss S, and Messer L (2009): An evidence-based assessment of the clinical guidelines for replanted avulsed teeth. Part II: prescription of systemic antibiotics. Dental Traumatology, 25(2): 158-164

25-Yingling N, Byrne B, and Hartwell G (2002): Antibiotic use by members of the American Association of Endodontists in the year 2000: report of a national survey. Journal of endodontics, 28(5): 396-404 